Article

\title{
Synthesis of New Amino- $\beta$-Cyclodextrin Polymer, Cross-Linked with Pyromellitic Dianhydride and Their Use for the Synthesis of Polymeric Cyclodextrin Based Nanoparticles
}

\author{
Kinga Kozieł (D), Jakub Lagiewka, Beata Girek, Agnieszka Folentarska, Tomasz Girek (D) and Wojciech Ciesielski *(D) \\ Faculty of Mathematics and Natural Science, Jan Dlugosz University in Czestochowa, Armii Krajowej Avenue, \\ 13/15, 42201 Czestochowa, Poland; kingakoziel123@gmail.com (K.K.); j.lagiewka17@gmail.com (J.Ł.); \\ b.girek@ajd.czest.pl (B.G.); a.folentraska@ajd.czest.pl (A.F.); t.girek@ajd.czest.pl (T.G.) \\ * Correspondence: wc@ajd.czest.pl or w.ciesielski@interia.pl
}

\section{check for}

updates

Citation: Kozieł, K.; Łagiewka, J.; Girek, B.; Folentarska, A.; Girek, T.; Ciesielski, W. Synthesis of New Amino- $\beta$-Cyclodextrin Polymer, Cross-Linked with Pyromellitic Dianhydride and Their Use for the Synthesis of Polymeric Cyclodextrin Based Nanoparticles. Polymers 2021 13, 1332. https://doi.org/10.3390/ polym 13081332

Academic Editor: Beom Soo Kim

Received: 14 March 2021

Accepted: 14 April 2021

Published: 19 April 2021

Publisher's Note: MDPI stays neutral with regard to jurisdictional claims in published maps and institutional affiliations.

Copyright: (C) 2021 by the authors. Licensee MDPI, Basel, Switzerland This article is an open access article distributed under the terms and conditions of the Creative Commons Attribution (CC BY) license (https:// creativecommons.org/licenses/by/ $4.0 /)$.
Abstract: New water soluble amino $\beta$-cyclodextrin-based polymer was synthesized by reaction between amino cyclodextrin derivatives and pyromellitic anhydride. This experiment presents amino derivatives, which were synthesized by attaching amino groups to $\beta$-cyclodextrins ( $\beta$-CDs) used mono-6-azido-6-deoxy- $\beta$-cyclodextrin $\left(\beta-\mathrm{CD}-\mathrm{N}_{3}\right)$ and triphenylphosphine $\left(\mathrm{Ph}_{3} \mathrm{P}\right)$ in anhydrous $\mathrm{N}, \mathrm{N}$-dimethylformamide (DMF). An amino blocking reaction was conducted. The obtained polymer was purified by ultrafiltration. In addition, an attempt was made to create nanospheres by encapsulating the polymer with chitosan (CT) in an acidic condition. For the first time, nanospheres were obtained in the reaction between an amino $\beta$-cyclodextrin polymer and chitosan. Scanning electron microscopy (SEM). ${ }^{1} \mathrm{H}$ NMR and ESI-MS methods for confirmation of reaction product and for structural characterization were employed. The differential scanning calorimetry (DSC) studies of polymers were also carried out.

Keywords: amino- $\beta$-cyclodextrin; polymerization; pyromellitic dianhydride; polyampholyte; nanoparticles

\section{Introduction}

Cyclodextrins (CDs) are cyclic oligomers produced by the enzymatic degradation of starch. CDs are composed of six, seven or eight glucopyranosyl units (named accordingly $\alpha-, \beta$ - or $\gamma$-CDs) linked together by a-1,4-bonds. All CDs are crystalline, homogeneous substances dissolving in water, having the shape of a ring tapering on one side and widening on the other [1]. As a consequence of the chair conformation of glucopyranose mers, all secondary hydroxyl groups at the $\mathrm{C} 2$ and $\mathrm{C} 3$ are on one of the two edges of the ring and all primary hydroxyl groups at the C6 on the other [2]. Many hydroxyl groups, especially having different properties, allow for the modification of cyclodextrins. They are carried out to expand their applications. Improvements in binding, selectivity or $\mathrm{pH}$ allow for the use of modified CDs as chemosensors, artificial enzymes or carriers [3]. The use of cyclodextrins as precursors to form derivatives and polymers is justified because of their biodegradability and total biocompatibility with human tissues [4]. We can also polymerize CDs to give them better stability and lower solubility [5-8]. The article presents a polymer of a new class of compounds crosslinked with dianhydrides, introducing anionic groups into the polymer network. It is a continuation of our previous work about $\beta$-cyclodextrin polymers crosslinked with pyromellitic dianhydride [9]. At the same time, keeping the amino group significantly improves the solubility of the system used. Therefore, a large group of researchers present CD polymers as compounds with potential medical use [10]. The presented polymer material can form hydrogels with many known polycations (chitosan, poly-L-lysine) and polyanions (alginic acid, pectin, or hyaluronic acid, etc.) [11-13]. $\beta$-cyclodextrins and their derivatives are successfully used as material for the formation 
of microspheres or nanospheres $[14,15]$. They create biodegradable spheres due to their hydrophobic properties $[16,17]$. Porous gel spheres with the ability to absorb/release substances [18] contained in them can be used as an additive to drugs to prolong their release [19-21]. The same properties allow for the control of fertilization in agriculture as it is broadly understood.

The amino $\beta$-cyclodextrin-based polymer contains a large number of anionic and cationic groups. On one hand, the polyelectrolyte properties of the support will facilitate the formation of complexes between the medicinal substances and support, and on the other hand will allow the biomembranes to freely penetrate using the specific properties of polyampholyte. The method of synthesis of a new cyclodextrin polymer having the status of polympholyte was compiled. In this regard, it was synthesized $\beta-\mathrm{CD}-\mathrm{NH}_{2}$ by reducing $\beta-C D-N_{3}$ using triphenylphosphine, followed by hydrolysis to give a product [22]. There was a need to protect the reactive functional group $-\mathrm{NH}_{2}$, with a protective group. Used for this a tert-butyloxycarbonyl group (BOC) [23-25]. The $\beta-C D-\mathrm{NH}_{2}$, was polymerized using crosslinking reaction [26-28]. As a crosslinking agent used pyromellitic dianhydride with $\mathrm{NaH}$. The reaction was carried out under strongly alkaline conditions necessary for deprotonation of glucose hydroxyl groups unit. An ultrafiltration process was used to separate the polymer due to the particle size by $76 \mathrm{~mm}, 5000 \mathrm{Da}$ membranes selected. Two types of measurement were selected: with molecular weight higher then $5000 \mathrm{Da}$ (PHMW) and with a molecular weight lower then 5000 Da (PLMW). The polymer PHMW was used to create nanoparticles. ESI MS analysis was performed to check the molecular mass of the $\beta-\mathrm{CD}-\mathrm{NH}_{2}$. The ${ }^{1} \mathrm{H}$ NMR and DSC measurement for the structural characterization of the polymers were conducted. A detailed SEM analysis of several different polymer solutions in a certain concentration range was performed. In previous works [9], a full characterization of similar systems was performed. The presented work is a continuation of the above-mentioned research conducted by our team. Future studies were set up to check the swelling properties and release kinetics of the cross-linked hydrogel membrane; e.g., using the methods described by M.R. El-Aassar et al. [21]. Our new results will be published soon.

\section{Materials and Methods}

\subsection{Reagents and Solvents}

$\beta$-Cyclodextrin ( $\beta C D), N, N$-dimethyl formamide (DMF), calcium hydride and sodium hydride were purchased from Sigma-Aldrich, St. Louis, MO, USA. DMF was distilled under vacuum. The dried DMF was stored in a dark bottle over calcium hydride. Sodium hydride (60\% in oil) was dried by hexane. Chitosan was purchased from Acros Organics, Pittsburgh, USA, triphenylphosphine $\left(\mathrm{PPh}_{3}\right)$ was purchased from Fluka Analytical, Monte Carlo, USA, pyromellitic dianhydride (PA) was purchased from Alfa Aesar, Ward Hill, Massachusetts, USA. Acetone, $p$-dioxane, acetic acid and hexane were purchased from Chempur, Piekary Slaskie, Poland. Sodium bicarbonate was purchased from Stanlab, Lublin, Poland. Di-tert-butyl dicarbonate $\left(\mathrm{BOC}_{2} \mathrm{O}\right)$ was purchased from Merck $\mathrm{KGaA}$, Darmstadt, Germany. Mono-6-azido-6-deoxy- $\beta$-cyclodextrin $\left(N_{3}-\beta-C D\right)$ was synthesized according to procedure developed by Tang at al. [22].

\subsubsection{Synthesis of Mono-6-Amino-6-Deoxy- $\beta$-Cyclodextrin $(A \beta C D)$}

Mono-6-azido-6-deoxy- $\beta$-cyclodextrin $(1.5 \mathrm{~g}, 1.29 \mathrm{mmol})$ was dissolved in DMF $(2.2 \mathrm{~mL})$. Triphenylphosphine $\left(\mathrm{Ph}_{3} \mathrm{P}\right)(0.36 \mathrm{~g}, 1.37 \mathrm{mmol})$ was added with vigorous stirring for $2 \mathrm{~h}$ at room temperature. Later $\mathrm{H}_{2} \mathrm{O}(0.26 \mathrm{~mL})$ was added and the solution was heated at $90{ }^{\circ} \mathrm{C}$ for $3 \mathrm{~h}$. After this time the reaction mixture was cooled to room temperature. The reaction product was precipitated and washed with acetone $(200 \mathrm{~mL})$ [22], and finally dried in a vacuum desiccator at room temperature. Yield: $89 \%$. 
${ }^{1} \mathrm{H}-\mathrm{NMR} .\left(\mathrm{D}_{2} \mathrm{O}\right),(\delta: \mathrm{ppm}):$ 5.03-4.92 (d, 7H, H-1), 3.95-3.65 (m, 28H, H-3, H-5, H-6), 3.60-3.45 (m, 14H, H-2, H-4), 3.11-3.01 (t, H-6' a), 2.85-2.78 (k, H-6 b). ${ }^{1} \mathrm{H}-\mathrm{NMR}$. (DMSO-d6), (ঠ: ppm): 5.90-5.55 (m, 14H, OH-2, OH-3), 4.95-4.75 (d, 7H, H-1), 4.60-4.35 (d, 6H OH-1), 3.75-3.55 (m, 28H, H-3, H-5, H-6). MS (ESI), ( $m / z)$ : Calculated: 1134.3; Found: 1134.27 [M $-\mathrm{H}]^{+}$.

\subsubsection{Synthesis of Blocking the Amine Group by BOC (BA $\beta C D)$}

Mono-6-amino-6-deoxy- $\beta$-cyclodextrin $(1 \mathrm{~g}, 0.88 \mathrm{mmol})$ was dissolved in $\mathrm{H}_{2} \mathrm{O}(27 \mathrm{~mL})$. Sodium bicarbonate $(2 \mathrm{~g}, 23.81 \mathrm{mmol})$ was added with vigorous stirring. The solution was cooled to $5{ }^{\circ} \mathrm{C}$ and di-tert-butyl dicarbonate $(1.5 \mathrm{~g}, 6.87 \mathrm{mmol})$ dissolved in solution of p-dioxane $(5 \mathrm{~mL})$ was added. The mixture was cooled to $2^{\circ} \mathrm{C}$ and stirred for $1 \mathrm{~h}$. It was left overnight at room temperature. The product was precipitated with acetone $(200 \mathrm{~mL})$ and dried in a vacuum desiccator at room temperature. Yield: 95\%. ${ }^{1} \mathrm{H}-\mathrm{NMR}\left(\mathrm{D}_{2} \mathrm{O}\right),(\delta: \mathrm{ppm})$ : 5.10-4.93 (d, 7H, H-1), 4.13-3.62 (m, 28H, H-3, H-5, H-6), 3.60-3.45 (m, 14H, H-2, H-4), 2.77-2.63 (k, H-6'a), 1,40 (s, 9H, BOC).

2.1.3. Synthesis of $\beta-C D-N_{2}$ Polymer Crosslinked with Pyromellitic Anhydride (PA $\left.\beta C D\right)$

$\beta$-CD-NH-BOC (2 g, $1.62 \mathrm{mmol})$ was dissolved in DMF $(20 \mathrm{~mL}) . \mathrm{NaH}(0.18 \mathrm{~g}, 7.5 \mathrm{mmol})$ was washed with hexane and added in one portion with vigorous stirring. The mixture was stirred for $24 \mathrm{~h}$. After this time, PA $(1.74 \mathrm{~g}, 7.97 \mathrm{mmol})$ was added in one portion and solution was mixed for another $24 \mathrm{~h}$. The product was precipitated with acetone dried in a vacuum desiccator at room temperature [9].

\subsubsection{Separation of the Polymer Due to Particle Size}

CD polymer sample was dissolved in water and separated by ultrafiltration process at Millipore UF Stirred Cell 76 mm with Ultrafiltration Membrane, Regenerated Cellulose PLCC 5000 Da. The pressure of nitrogen gas was 2.2 bar. The separated fractions were recovered and weighed.

\subsubsection{The Preparation of Nanospheres}

The $0.1 \%$ solution of chitosan $(25 \mathrm{~mL})$ in $1.75 \%$ acetic acid and a $0.1 \%$ aqueous solution of the resulting polymer $(25 \mathrm{~mL})$ was prepared. $5 \mathrm{~mL}$ chitosan solution were poured into 5 bottles and $0.25,1,2,2.5$ and $3 \mathrm{~mL}$ polymer solution were added in succession under magnetic stirring at room temperature [16].

\subsubsection{NMR Measurement}

${ }^{1} \mathrm{H}-\mathrm{NMR}(600 \mathrm{MHz})$ spectra were recorded on a Avance II Bruker Ultrashield Plus spectrometer in a $5 \mathrm{~mm}$ sample tube, using $\mathrm{D}_{2} \mathrm{O}$ and DMSO as the solvents. All spectra were obtained at ambient temperature.

\subsubsection{ESI-MS Experiment}

The mass spectra (ESI-MS) were recorded on a Thermo Finnigan LCQ Fleet (Thermo Fisher Scientific Inc., San Jose, CA, USA) mass spectrometer.

\subsubsection{SEM Measurement}

Scanning electron microscopy (SEM) of polymer were evaluated on Vega 3, Tescan. All samples were subjected to $4 \mathrm{kV}$ beam energy. Samples of nanoparticles were analyzed by a Nova Nano SEM 200 microscope of up to $2 \mathrm{~nm}$ resolution and 70-500 $000 \times$ magnification equipped with a field FEG Schotky emitter (FEJ Europe Company, Hillsboro, OR, USA). All samples were subjected to $5 \mathrm{kV}$ beam energy. 


\subsubsection{DSC Measurement}

Differential scanning calorimetry (DSC) were recorded on a NETZSCH STA-409 simultaneous thermal analyzer (Selb, Germany), calibrated with standard aluminium of $99.99 \%$ purity. A sample of the tested material in corundum crucibles with non-hermetic lids was placed in a measuring chamber and heated in the temperature range $20-500{ }^{\circ} \mathrm{C}$ with the $5{ }^{\circ} \mathrm{C} \mathrm{min} / \mathrm{L}$ temperature rate. The measurements were duplicated. Recorded thermograms were analyzed with the NETZSCH-TAANALYSIS program.

\section{Results and Discussion}

\subsection{Synthesis of $P A B C D$}

In these studies pyromellitic dianhydride was used as a linker to synthesize polymer with a significant amount of anionic and cationic groups. Crosslinking reaction took place by deprotonating the hydroxyl groups at the $\mathrm{C} 2$-position with $\mathrm{NaH}$ attaching $\mathrm{PA}$ at this position [29]. Figure 1A illustrates this process. The molar ratio of the reactants was 1:4:4. Deprotonation and crosslinking took place in dry DMF. The solution turned to a gel upon addition of PA.

A

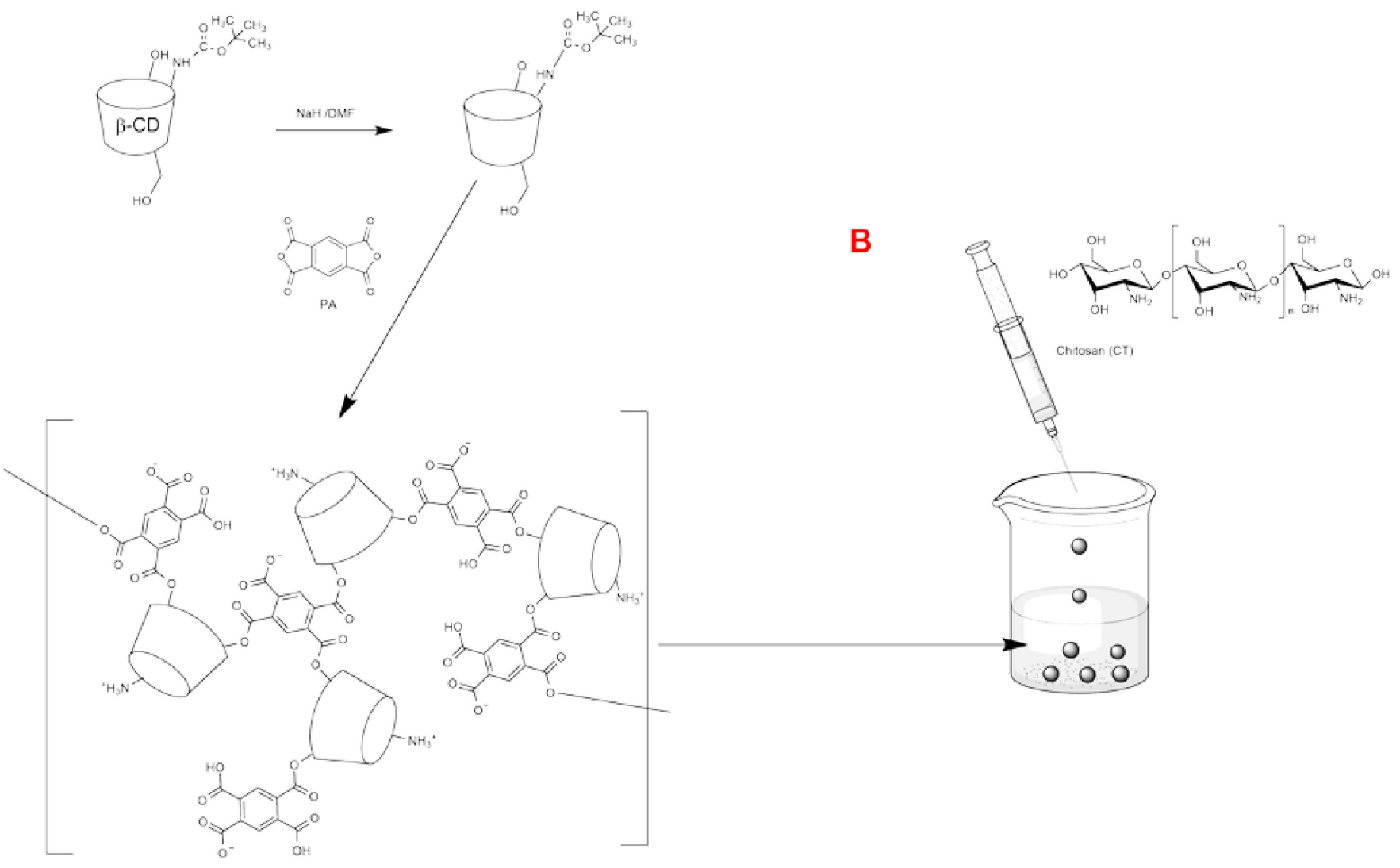

Figure 1. The scheme of polymer synthesis (A) and formation of spheres (B).

\subsection{Separation of the Polymer Due to Particle Size}

Samples obtained in this reaction were initially separated by ultrafiltration at Milipore UF Stirres Cell equipped with Ultrafiltration Membrane with the cut-off size of $5000 \mathrm{Da}$. Table 1 represents the results of the ultrafiltration experiment. 
Table 1. Ultrafiltration data for samples prepared of $A \beta C D, N a H$ and pyromellitic dianhydride.

\begin{tabular}{ccc}
\hline Cut-Off & Weight $[\mathbf{g}]$ & \% Of Whole Sample \\
\hline Whole sample & 2.00 & 100 \\
\hline PLMW & 1.02 & 51.00 \\
\hline PHMW & 0.50 & 25.00 \\
\hline
\end{tabular}

The experiment showed a quantitative advantage of PLMW over PHMW. We obtain PHMW in 25\%, and PLMW in 51\% yield, respectively. In the general sample, the mass of PLMW is twice as large as the mass of PHMW.

\subsection{The Preparation of Nanospheres}

The spheres were made using ionic gelation between the newly formed polymer and chitosan. The chitosan solution was dripped into the polymer solution with a syringe and needle. The formed drop hardened by falling into the solution. Nanospheres were created from the same reaction using an atomizer. The spheres were made with using a PHMW. Figure 1B illustrates this process.

\subsection{Spectroscopic Characterization}

The ${ }^{1} \mathrm{H}$ NMR spectra of $\mathrm{A} \beta C \mathrm{C}$ is shown in Figure 2. $\mathrm{D}_{2} \mathrm{O}$ was used as the solvent. The most important part of the spectrum presented are the two signals coming from the $\mathrm{H} 9$ protons resonance, the carbon-nitrogen bond with the amino group. They are respectively: 3.05 ppm (dd) and 2.81 ppm (dd).

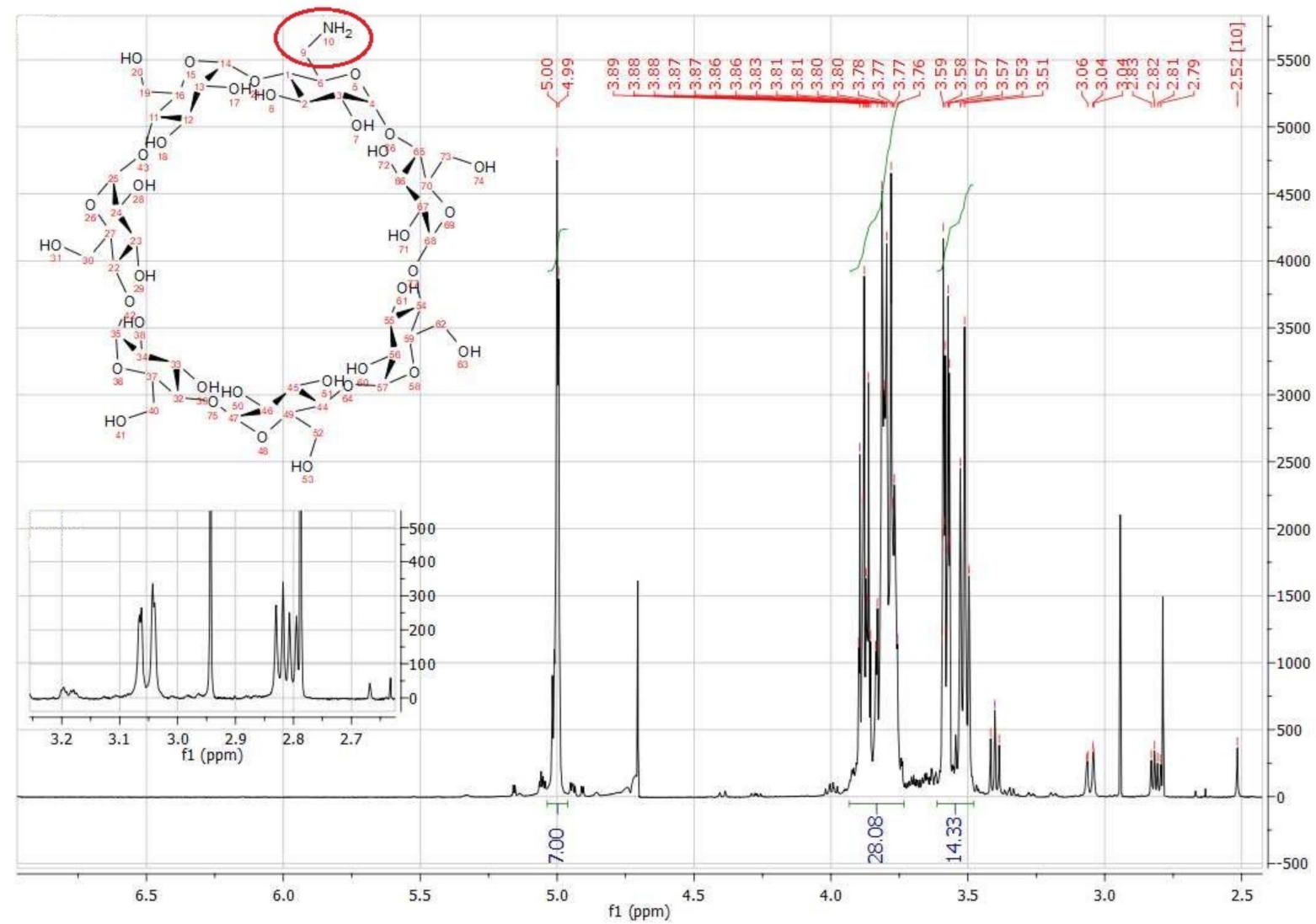

Figure 2. The ${ }^{1} \mathrm{H}$ NMR spectra of $\mathrm{A} \beta C D$. 


\subsection{Spectrometric Characteristics}

The mass spectra (ESI-MS) of A $\beta C D$ is shown in Figure 3. On the fragment of the spectrum, here is a visible parent peak with the value $m / z=1134.27\left(\mathrm{M}+\mathrm{H}^{+}\right)$, corresponding to the literature values for $\mathrm{A} \beta \mathrm{CD}$ : 1134.30 .

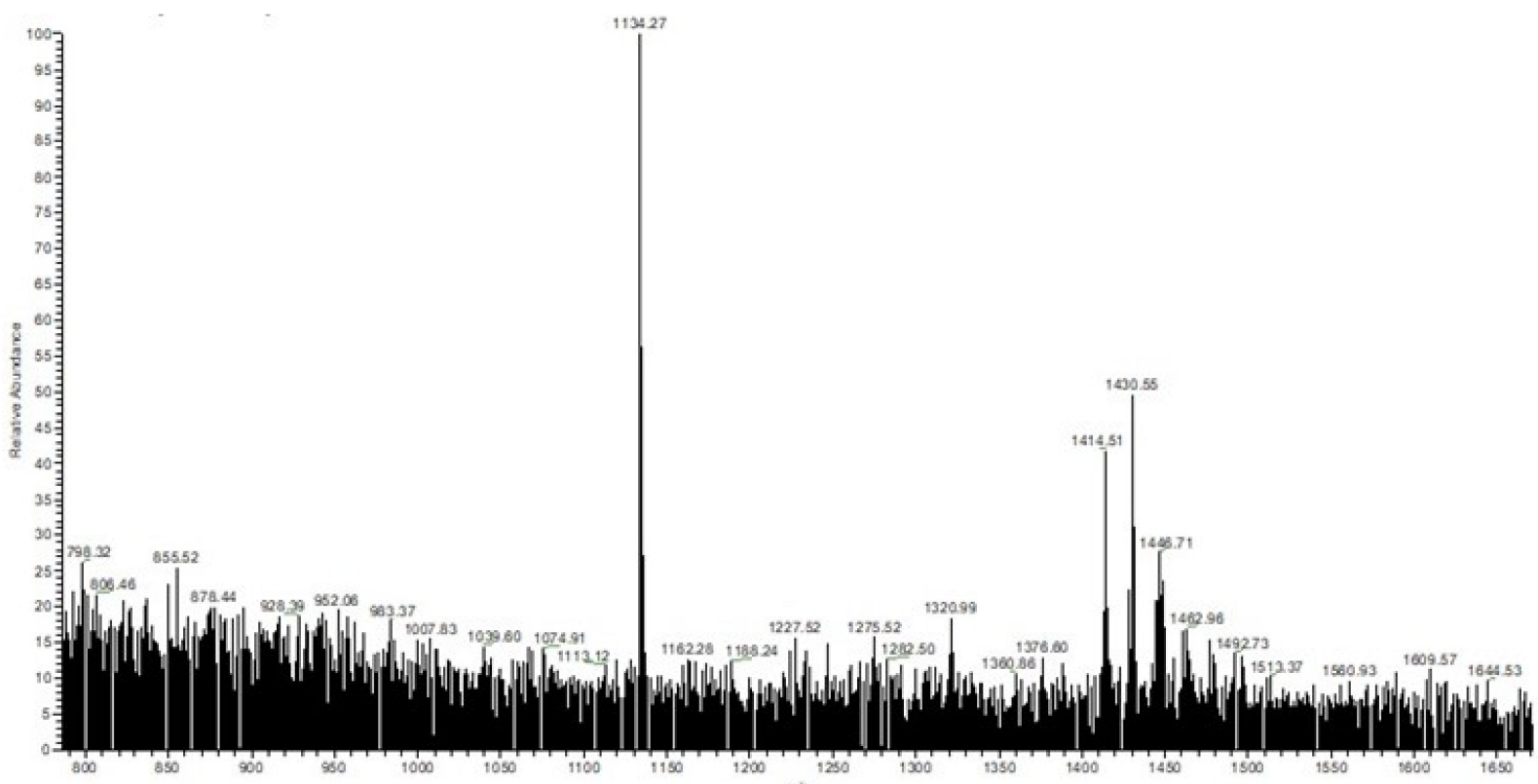

Figure 3. Fragment of the mass spectra (ESI-MS) of A $\beta C D$.

\subsection{SEM Characterization}

The structure of polymer was analyzed with the Scanning Electron Microscopy, samples $\beta C D, P A \beta C D$, PLMW and PHMW were analyzed, respectively. Nanospheres made of PHMW were also analyzed.

Figure 4 shows morphologies of $\beta C D$ monomer (A). It has a non-smooth surface with cracks, which can be attributed to the crystallinity of cyclodextrin. On the other hand, the right photo presents the PA $\beta C D$. (B). The polymer particles are packed in a network with a large number of micropores. The polymer contains clusters of separate particles and has larger holes, but the surface of a single particle is tightly packed with small holes. SEM analysis of the polymer after ultrafiltration was also performed. At Figure $5 \mathrm{~A}, \mathrm{~B}$ is shown the crystal structure of the PLMW. The structure resembles PA $\beta C D$. The same figure also shows large crystals from the high molecular product, most likely because of incomplete ultrafiltration. Figure 5 C,D shows the crystal structure of the PHMW which has a smooth surface, and the particles are packed much tighter. The pores are less visible.

SEM analysis was also performed for three solutions containing nanospheres. Samples of the finished suspension containing 0.25 (1), 1 (2) and 2 (3) $\mathrm{mL}$ solution of $(0.1 \%)$ polymer in acidic solution $(0.1 \%)$ of chitosan were used for the test. The solution concentrations were $5 \%, 25 \%$ and $40 \%$, respectively. As shown in Figures 6-8, the SEM characterization confirmed the formation of nanospheres. Pictures with magnification of 20,000 (A), 50,000 (B) and 100,000 times (C) were taken for each solution. 

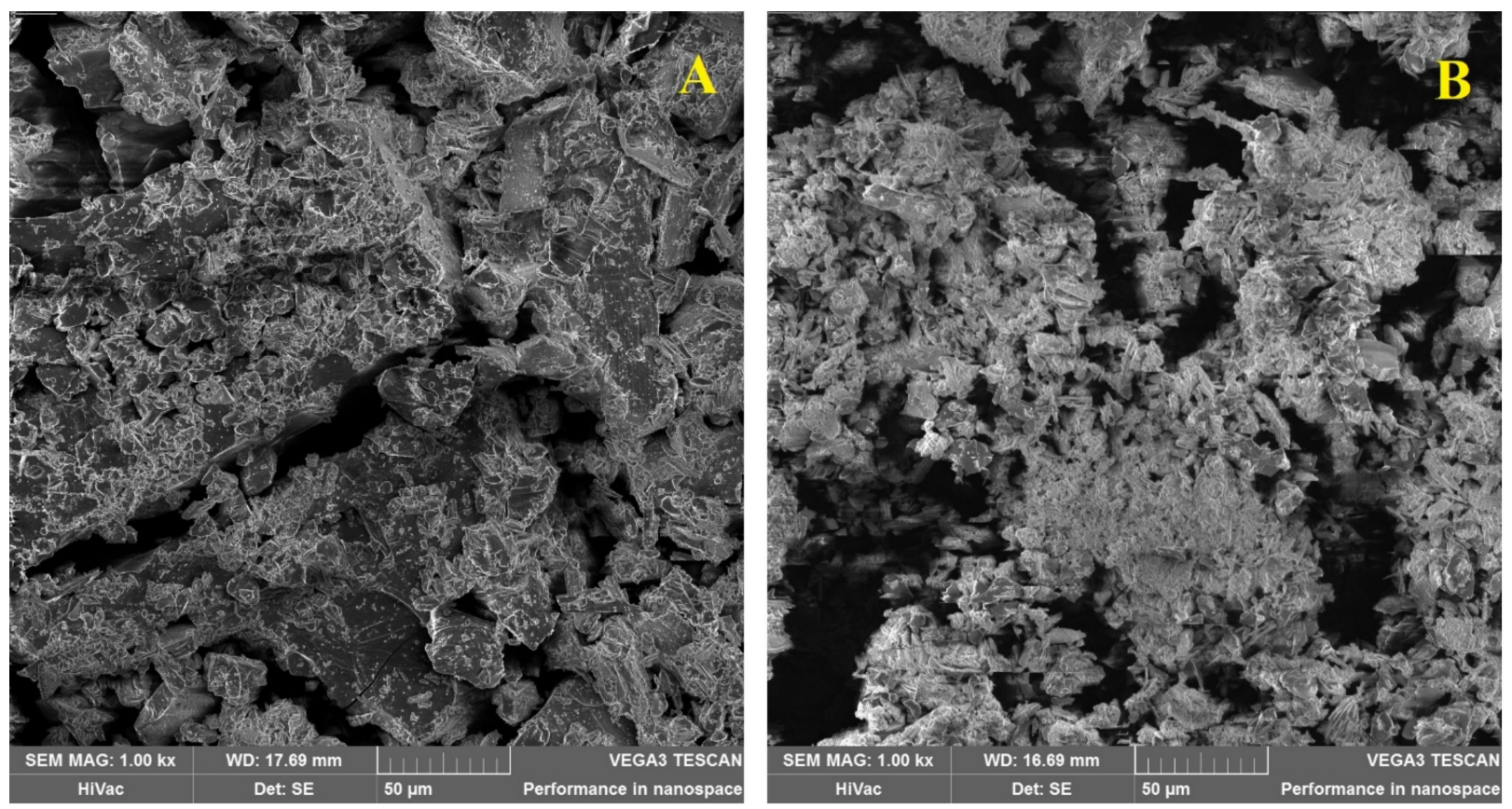

Figure 4. SEM imagines of $(A)$ the $\beta C D(1000 \times$ zoom $)(B)$ the $\operatorname{Pa} \beta C D(1000 \times$ zoom $)$.
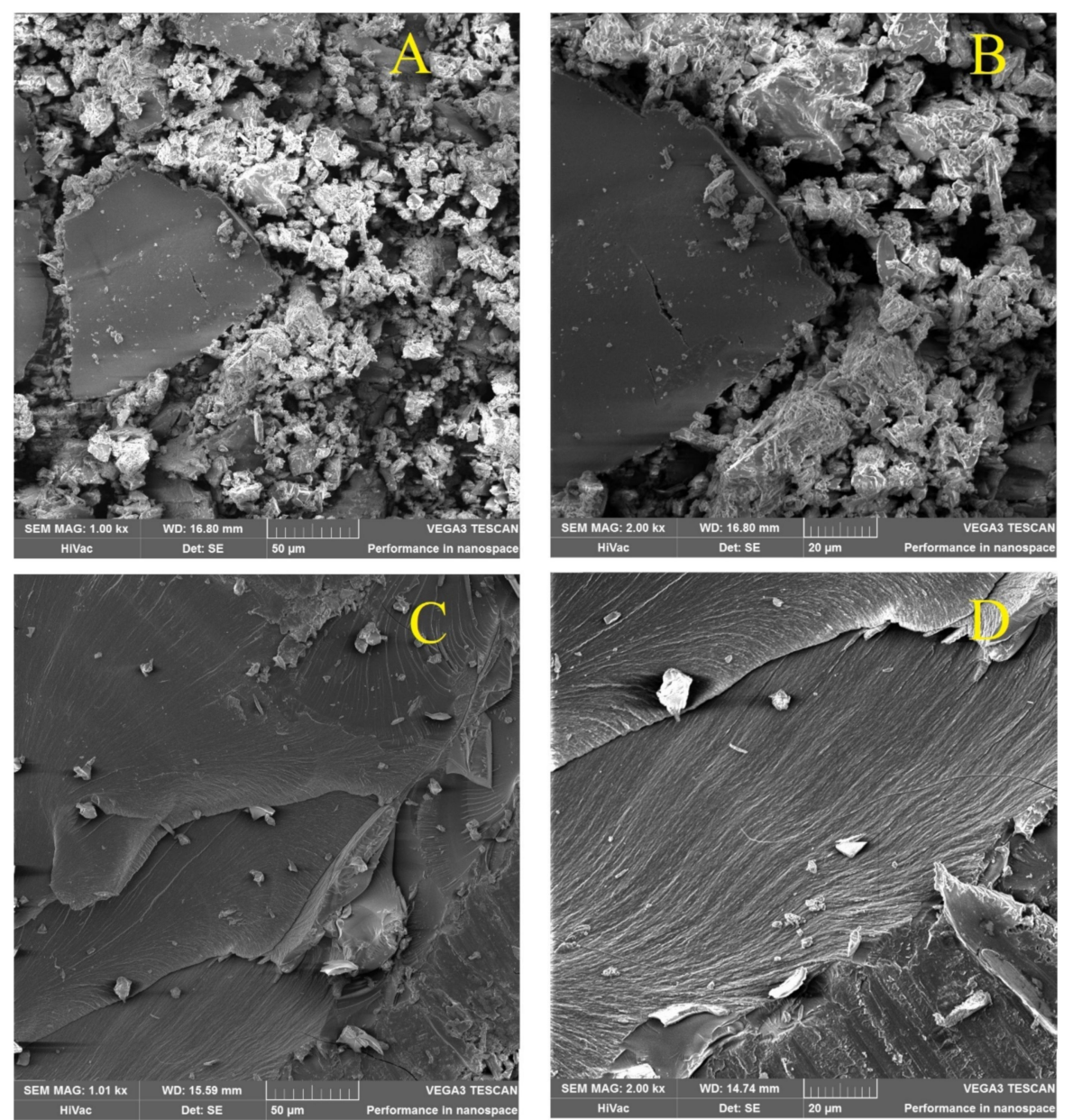

Figure 5. Crystal structure of (A) PLMW (1000× zoom), (B) PLMW (2000× zoom), (C) PHMW $(1000 \times$ zoom), (D) PHMW (1000× zoom). 


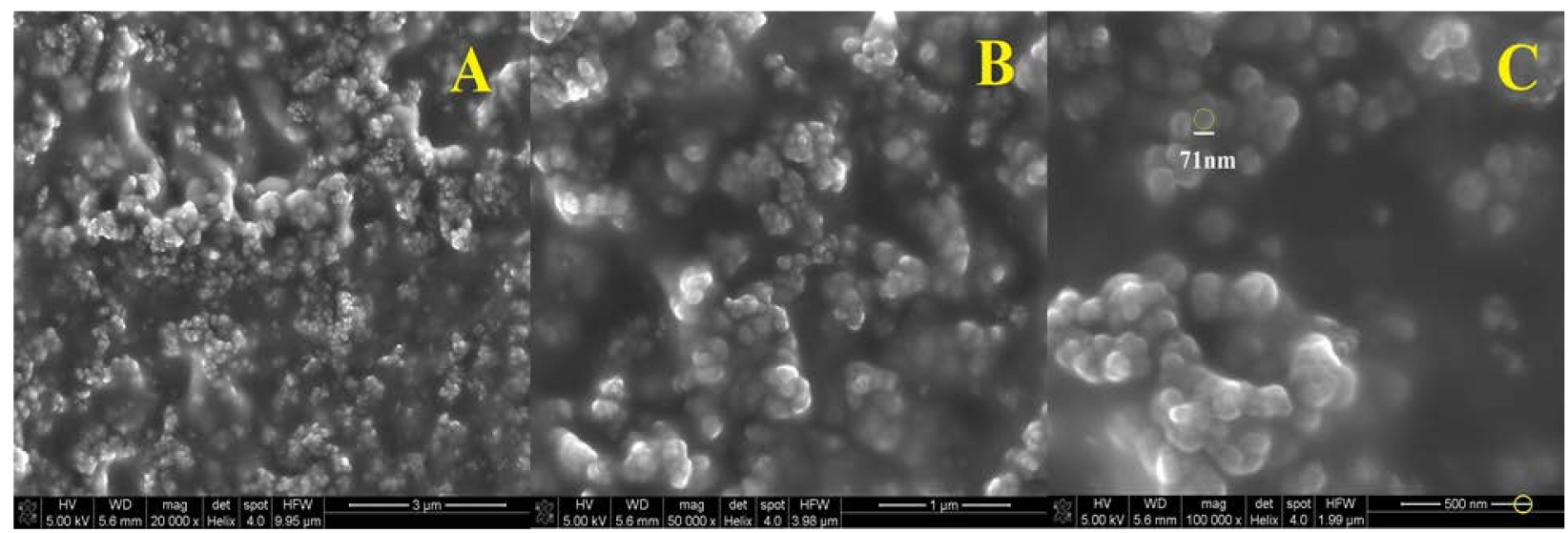

Figure 6. SEM imagines of nanospheres suspension 1 enlarged 20,000 times (A), 50,000 times (B) and 100,000 times (C).

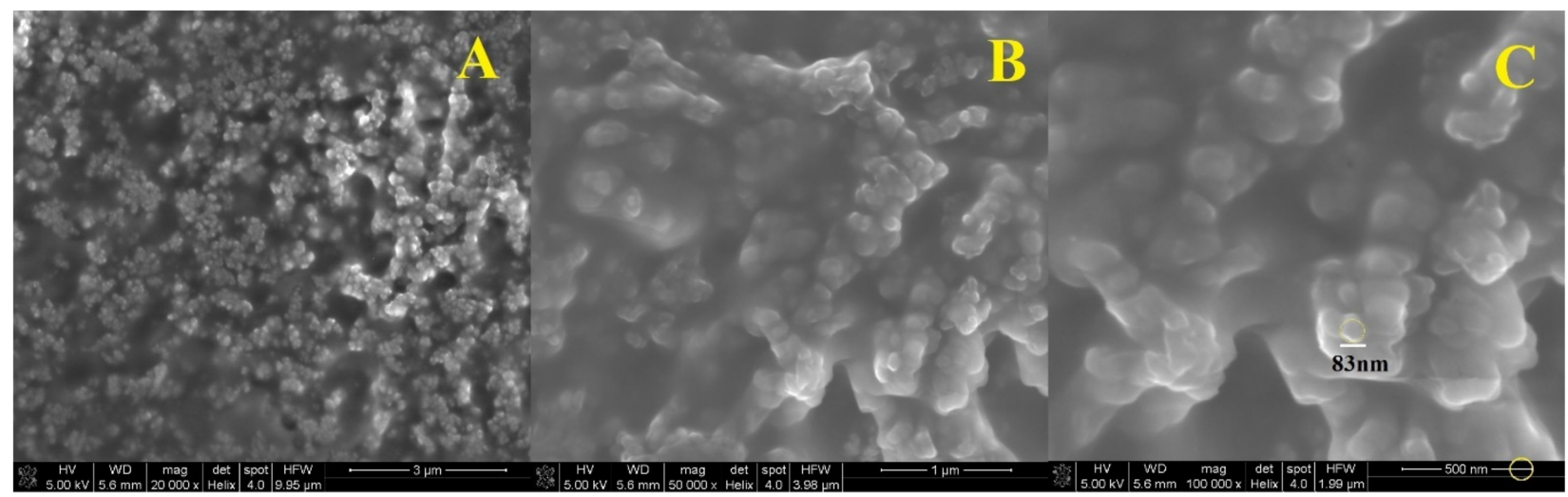

Figure 7. SEM imagines of nanospheres suspension 2 enlarged 20,000 times (A), 50,000 times (B) and 100,000 times (C).

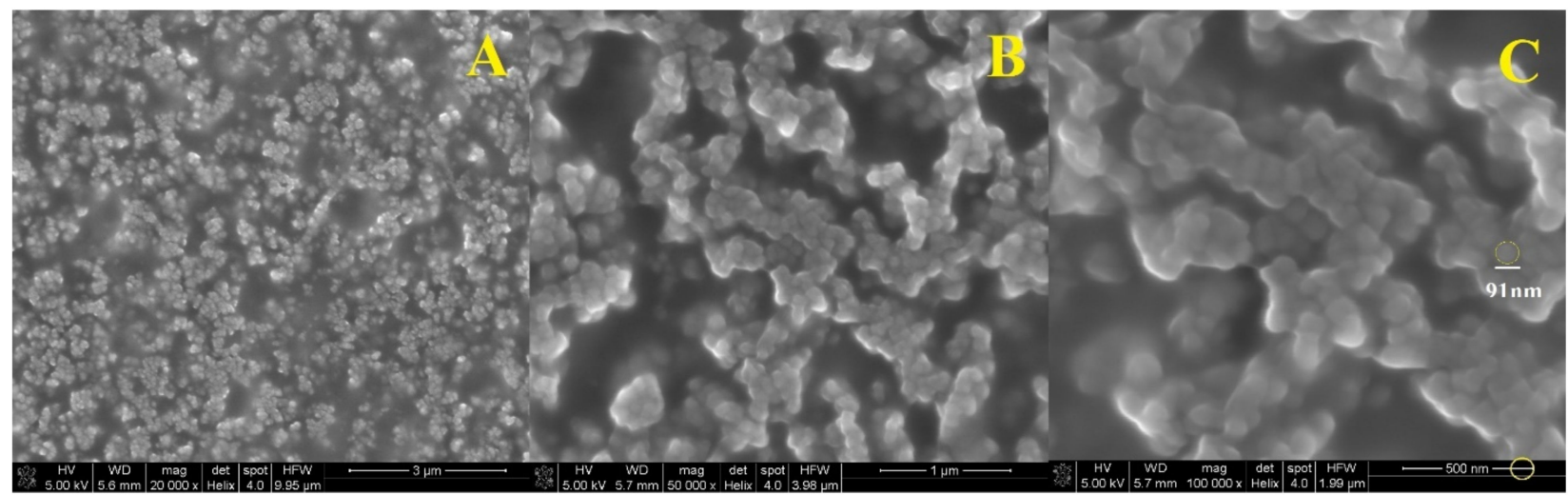

Figure 8. SEM imagines of nanospheres suspension 3 enlarged 20,000 times (A), 50,000 times (B) and 100,000 times (C).

It can be seen that the polymer in combination with chitosan gives spherical particles with a relatively homogeneous surface. Examination of the samples showed that the spheres in the solution are in the form of larger aggregates, and it was not possible to obtain a suspension of separate spheres. In Figure 6 is the SEM photo of suspension 1, where the diameter of one nanosphere was about $71 \mathrm{~nm}$ (Figure 6C). The morphology of suspension 2 showed that the particle size was about $83 \mathrm{~nm}$ (Figure 7C). The diameter of the sphere from Figure $8 \mathrm{C}$ was about $91 \mathrm{~nm}$ (suspension 3). The size of the nanospheres depends on the concentration of the polymer in chitosan. The higher concentration gives the larger particle diameter. 


\subsection{Differential Scanning Calorimetry Analysis}

In the $\beta$-CD DSC diagram (Figure 9) two melting peaks at $99.9^{\circ} \mathrm{C}$ and $274.8^{\circ} \mathrm{C}$ were found to be related to oxidation or elimination of water [30]. In the first one, the weight loss was $8.64 \%$, with the next at $50.18 \%$. The shape of corresponding parts of DSC diagram of low molecular weight polymer (Figure 10) confirms a different type of water coordination (compared to pure $\beta-\mathrm{CD}$ ), as well as its three-stage removal. This is indicated by the presence of small peaks at about $59.1{ }^{\circ} \mathrm{C}, 92{ }^{\circ} \mathrm{C}$ and $135.9^{\circ} \mathrm{C}$. In the study of the high molecular weight polymer (Figure 11) a glass transition point at about $418.8^{\circ} \mathrm{C}$ was demonstrated. In all cases, the exothermic effects had a different maximum. As the molecular weight increased, the maximum of the exothermic effects decreased.

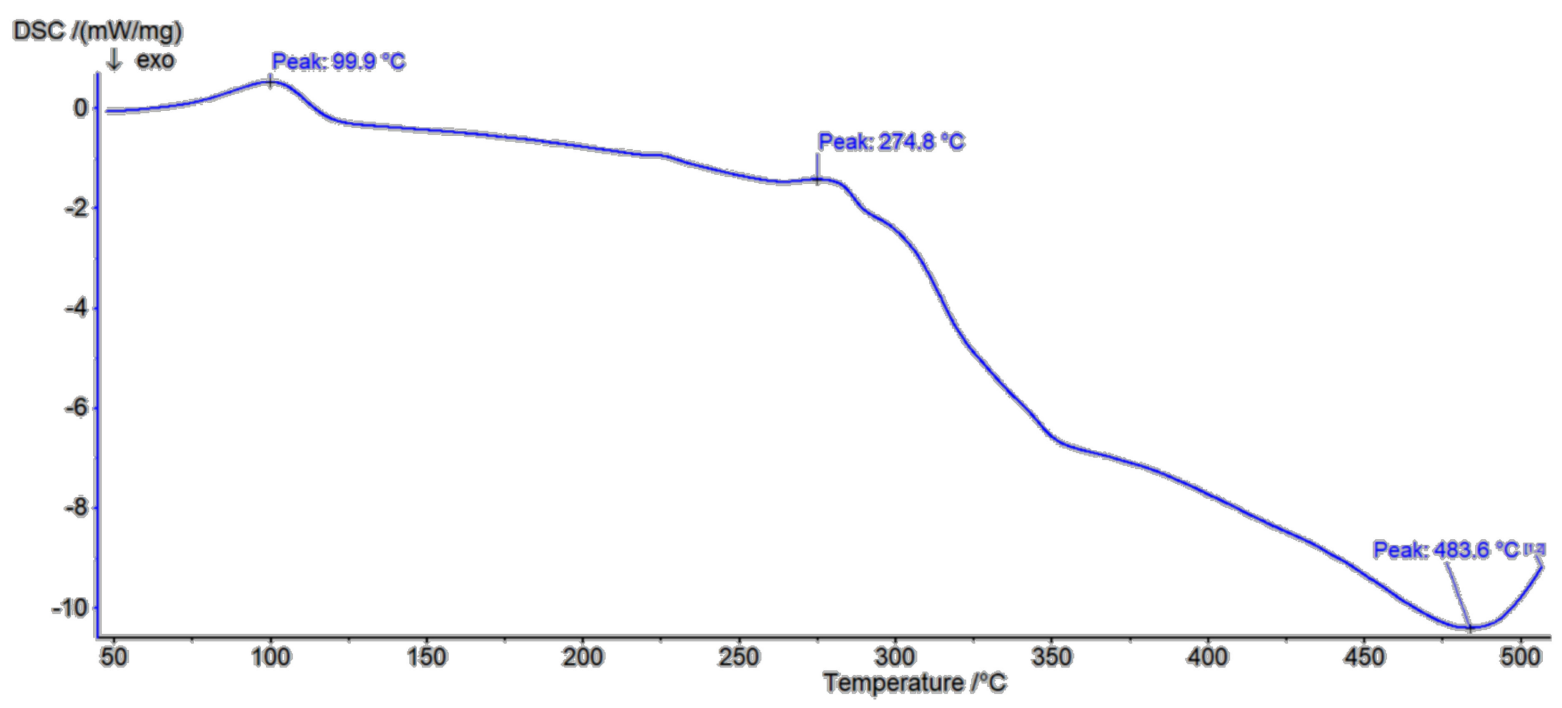

Figure 9. DSC spectra of $\beta$-cyclodextrin.

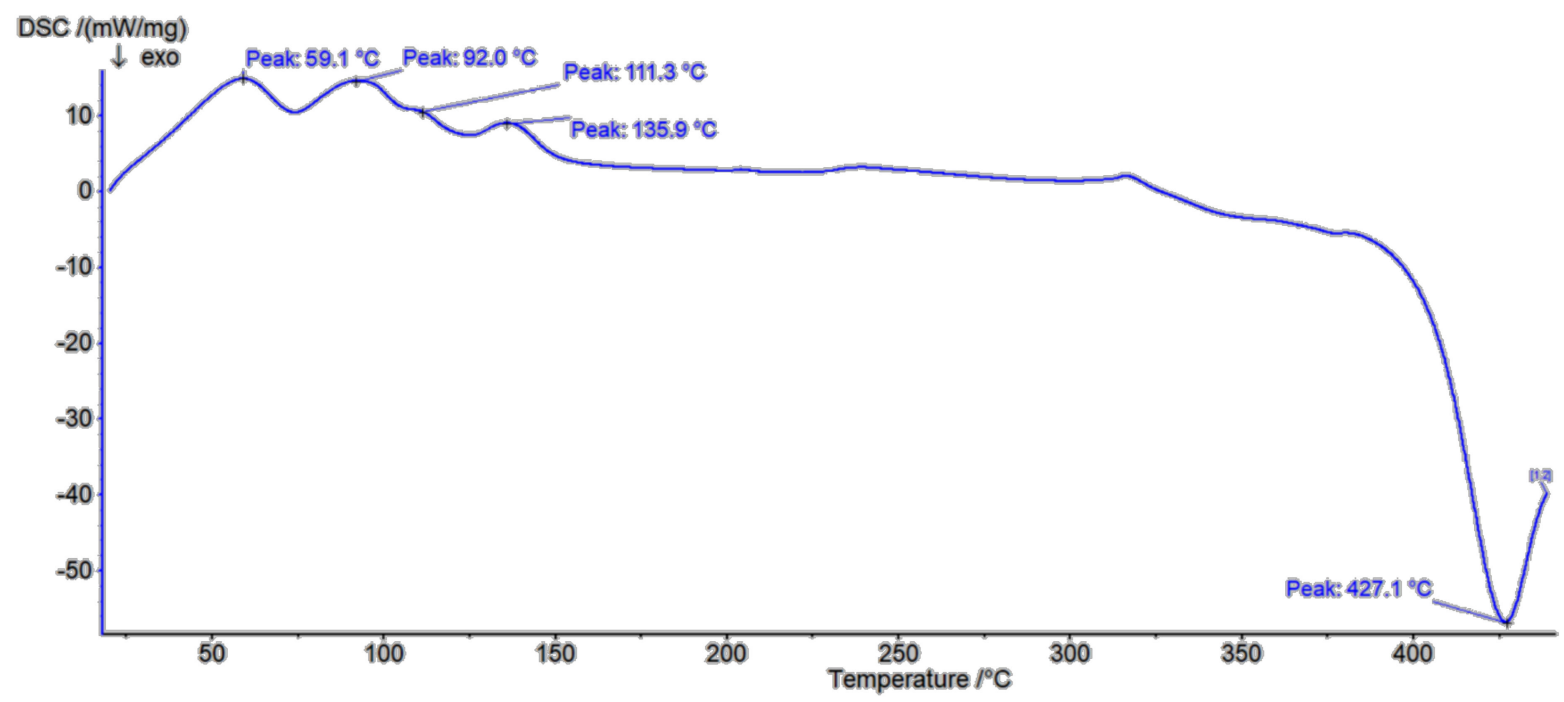

Figure 10. DSC spectra of PLMW. 


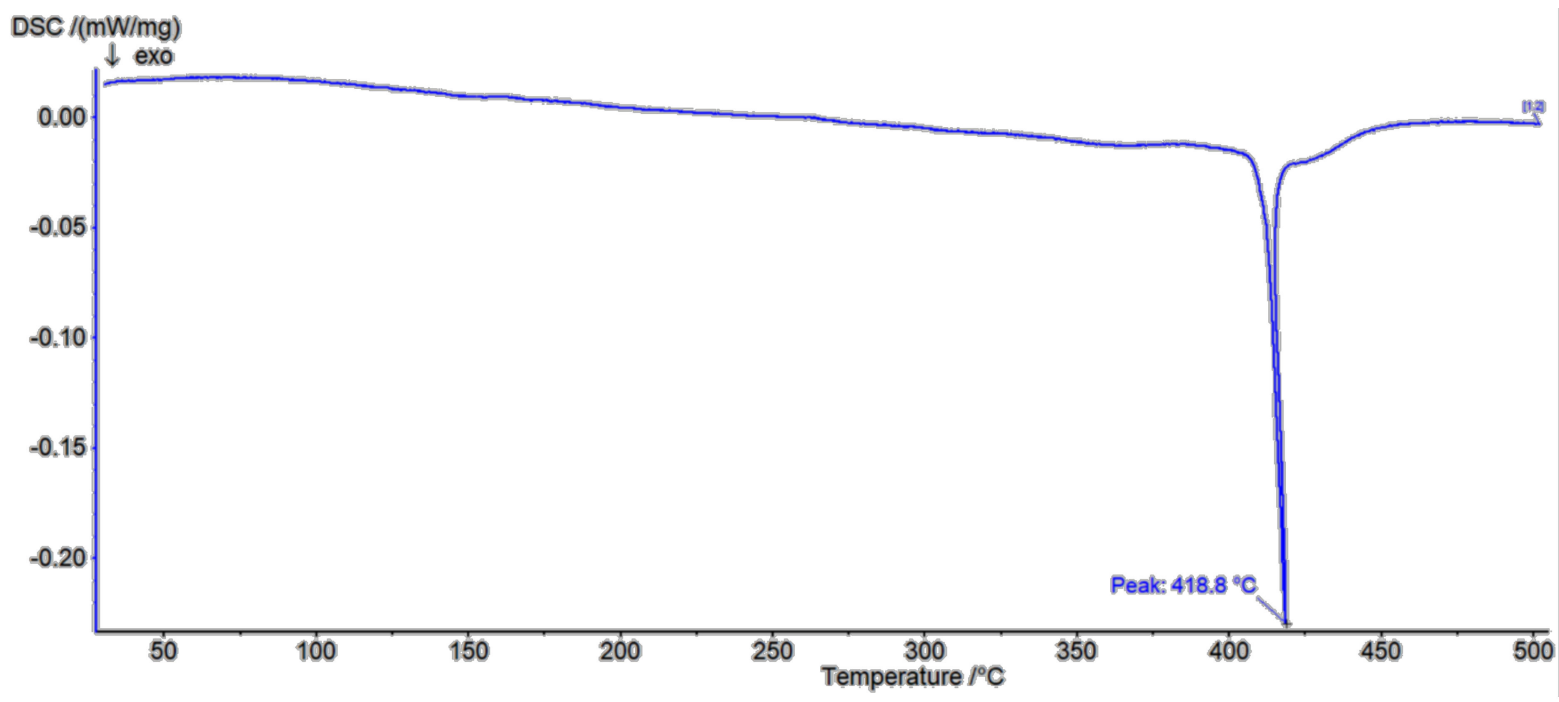

Figure 11. DSC spectra of PHMW DSC spectra of high molecular weight polymer.

\section{Conclusions}

New, water soluble, polyampholyte CD polymer was prepared by crosslinking amino$\beta$-cyclodextrin with pyromellitic dianhydride. The ${ }^{1} \mathrm{H}$ NMR and ESI-MS studies confirmed the products of indirect reactions. The separation of the polymer due to particle size by ultrafiltration process was employed. The division of the polymer with respect to the molecular weight showed an unequal mass ratio between the high and low molecular weight product. The analysis of the formed polymer showed a change in surface area relative to pure $\beta$-cyclodextrin. For the first time, nanospheres were obtained in the reaction between an amino $\beta$-cyclodextrin polymer and chitosan. The SEM imagines of nanospheres confirmed the ionic gelation of the polymer with chitosan. Obtained nanospheres having a diameter of less then $90 \mathrm{~nm}$ SEM analysis showed the formation of nanoparticles, the diameter of which varies with the concentration of the polymer. Nanospheres can be precursors for the encapsulation of substances used in pharmacology and agriculture.

Author Contributions: Conceptualization, T.G.; Validation, T.G., W.C.; Investigation, B.G., K.K., J.Ł., A.F.; Data Curation, B.G., K.K., J.Ł., A.F.; Writing-Original Draft Preparation, K.K., T.G.; WritingReview \& Editing, T.G. and W.C.; Visualization, W.C.; Supervision, T.G., W.C.; Funding Acquisition, T.G. All authors have read and agreed to the published version of the manuscript.

Funding: This research received no external funding.

Institutional Review Board Statement: Not Applicable.

Informed Consent Statement: Not Applicable.

Data Availability Statement: Data is contained within the article.

Conflicts of Interest: The authors declare no conflict of interest.

\section{References}

1. Szejtli, J. Introduction and general overview of cyclodextrin chemistry. Chem. Rev. 1998, 98, 1743-1754. [CrossRef] [PubMed]

2. Dodziuk, H. Cyclodextrins and Their Complexes: Chemistry, Analytical Methods, Applications; Wiley-VCH: Weinheim, Germany, 2006; pp. 1-489. [CrossRef]

3. Sliwa, W.; Girek, T. Cyclodextrins: Properties and Applications; Wiley-VCH: Weinheim, Germany, 2017; p. 336.

4. Davis, M.E.; Brewster, M.E. Cyclodextrin-based pharmaceutics: Past, present and future. Nat. Rev. Drug Discov. 2004, 3, $1023-1035$. [CrossRef] [PubMed]

5. Pellicer, J.A.; Rodríguez-López, M.I.; Fortea, M.I.; Lucas-Abellán, C.; Mercader-Ros, M.T.; López-Miranda, S.; Gómez-López, V.M.; Semeraro, P.; Cosma, P.; Fini, P. Adsorption properties of $\beta$-and hydroxypropyl- $\beta$-cyclodextrins cross-linked with epichlorohydrin in aqueous solution. A sustainable recycling strategy in textile dyeing process. Polymers 2019, 11, 252. [CrossRef] [PubMed] 
6. Kobayashi, Y.; Nakamitsu, Y.; Zheng, Y.; Takashima, Y.; Yamaguchi, H.; Harada, A. Preparation of cyclodextrin-based porous polymeric membrane by bulk polymerization of ethyl acrylate in the presence of cyclodextrin. Polymer 2019, 177, $208-213$. [CrossRef]

7. Rojas-Aguirre, Y.; Torres-Mena, M.A.; López-Méndez, L.J.; Alcaraz-Estrada, S.L.; Guadarrama, P.; Urucha-Ortíz, J.M. PEGylated $\beta$-cyclodextrins: Click synthesis and in vitro biological insights. Carbohydr. Polym. 2019, 223, 115113. [CrossRef]

8. Malanga, M.; Seggio, M.; Kirejev, V.; Fraix, A.; Di Bari, I.; Fenyvesi, E.; Ericson, M.B.; Sortino, S. A phototherapeutic fluorescent $\beta$-cyclodextrin branched polymer delivering nitric oxide. Biomater. Sci. 2019, 7, 2272-2276. [CrossRef]

9. Girek, T.; Koziel, K.; Girek, B.; Ciesielski, W. CD oxyanions as a tool for synthesis of highly anionic cyclodextrin polymers. Polymers 2020, 12, 2845. [CrossRef]

10. Ciesielska, A.; Ciesielski, W.; Girek, B.; Girek, T.; Koziel, K.; Kulawik, D.; Lagiewka, J. Biomedical application of cyclodextrin polymers cross-linked via dianhydrides of carboxylic acids. Appl. Sci. 2020, 10, 8463. [CrossRef]

11. Concheiro, A.; Alvarez-Lorenzo, C. Chemically cross-linked and grafted cyclodextrin hydrogels: From nanostructures to drug-eluting medical devices. Adv. Drug Deliv. Rev. 2013, 65, 1188-1203. [CrossRef]

12. Folch-Cano, C.; Yazdani-Pedram, M.; Olea-Azar, C. Inclusion and functionalization of polymers with cyclodextrins: Current applications and future prospects. Molecules 2014, 19, 14066-14079. [CrossRef]

13. Sharaf, S.; El-Naggar, M.E. Wound dressing properties of cationized cotton fabric treated with carrageenan/cyclodextrin hydrogel loaded with honey bee propolis extract. Int. J. Biol. Macromol. 2019, 133, 583-591. [CrossRef]

14. Athmouni, K.; Belhaj, D.; Gammoudi, S.; El Feki, A.; Ayadi, H. Nano-encapsulation using macrocyclic carbohydrate polymers ( $\beta$-cyclodextrins) of Periploca angustifolia extract: Physical stability and protective effect against cadmium-induced alterations in HepG2 cells. Int. J. Biol. Macromol. 2019, 125, 711-720. [CrossRef] [PubMed]

15. Lu, P.; Cheng, J.; Li, Y.; Li, L.; Wang, Q.; He, C. Novel porous beta-cyclodextrin/pillar[5]arene copolymer for rapid removal of organic pollutants from water. Carbohydr. Polym. 2019, 216, 149-156. [CrossRef] [PubMed]

16. Calvo, P.; Remuñán-López, C.; Vila-Jato, J.L.; Alonso, M.J. Novel hydrophilic chitosan-polyethylene oxide nanoparticles as protein carriers. J. Appl. Polym. Sci. 1997, 63, 125-132. [CrossRef]

17. Gavini, E.; Rassu, G.; Haukvik, T.; Lanni, C.; Racchi, M.; Giunchedi, P. Mucoadhesive microspheres for nasal administration of cyclodextrins. J. Drug Target. 2009, 17, 168-179. [CrossRef]

18. Radwan, E.K.; Kafafy, H.; El-Wakeel, S.T.; Shaheen, T.I.; Gad-Allah, T.A.; El-Kalliny, A.S.; El-Naggar, M.E. Remediation of Cd(II) and reactive red 195 dye in wastewater by nanosized gels of grafted carboxymethyl cellulose. Cellulose 2018, 25, 6645-6660. [CrossRef]

19. Abdelgawad, A.M.; El-Naggar, M.E.; Elsherbiny, D.A.; Ali, S.; Abdel-Aziz, M.S.; Abdel-Monem, Y.K. Antibacterial carrageenan/cellulose nanocrystal system loaded with silver nanoparticles, prepared via solid-state technique. J. Environ. Chem. Eng. 2020, 8, 104276. [CrossRef]

20. Elsherbiny, D.A.; Abdelgawad, A.M.; El-Naggar, M.E.; El-Sherbiny, R.A.; El-Rafie, M.H.; El-Sayed, I.E.-T. Synthesis, antimicrobial activity, and sustainable release of novel $\alpha$-aminophosphonate derivatives loaded carrageenan cryogel. Int. J. Biol. Macromol. 2020, 163, 96-107. [CrossRef]

21. El-Aassar, M.R.; Hafez, E.E.; El-Deeb, N.M.; Fouda, M.M.G. Microencapsulation of lectin anti-cancer agent and controlled release by alginate beads, biosafety approach. Int. J. Biol. Macromol. 2014, 69, 88-94. [CrossRef]

22. Tang, W.; Ng, S.-C. Facile synthesis of mono-6-amino-6-deoxy-[alpha]-, [beta]-, [gamma]-cyclodextrin hydrochlorides for molecular recognition, chiral separation and drug delivery. Nat. Protoc. 2008, 3, 691-697. [CrossRef]

23. Viswanadham, B.; Mahomed, A.S.; Friedrich, H.B.; Singh, S. Efficient and expeditious chemoselective BOC protection of amines in catalyst and solvent-free media. Res. Chem. Intermed. 2017, 43, 1355-1363. [CrossRef]

24. Azizi, N.; Shirdel, F. Sustainable and chemoselective N-Boc protection of amines in biodegradable deep eutectic solvent. Mon. Chem. Chem. Mon. 2017, 148, 1069-1074. [CrossRef]

25. Servín, F.A.; Romero, J.A.; Aguirre, G.; Grotjahn, D.; Somanathan, R.; Chávez, D. General method for selective mono-boc protection of diamines and thereof. J. Mex. Chem. Soc. 2017, 61, 23-27. [CrossRef]

26. Tabasso, S.; Calcio Gaudino, E.; Acciardo, E.; Manzoli, M.; Giacomino, A.; Cravotto, G. Microwave-assisted dehydrogenative cross coupling reactions in $\gamma$-valerolactone with a reusable Pd/ $\beta$-cyclodextrin crosslinked catalyst. Molecules 2019, 24, 288. [CrossRef]

27. Tu, Y.; Xu, G.; Jiang, L.; Hu, X.; Xu, J.; Xie, X.; Li, A. Amphiphilic hyper-crosslinked porous cyclodextrin polymer with high specific surface area for rapid removal of organic micropollutants. Chem. Eng. J. 2020, 382, 123015. [CrossRef]

28. Rojas, M.J.; Amaral-Fonseca, M.; Zanin, G.M.; Fernandez-Lafuente, R.; Giordano, R.d.L.C.; Tardioli, P.W. Preparation of crosslinked enzyme aggregates of a thermostable cyclodextrin glucosyltransferase from Thermoanaerobacter sp. Critical effect of the crosslinking agent. Catalysts 2019, 9, 120. [CrossRef]

29. Rong, D.; D'Souza, V.T. A convenient method for functionalization of the 2-position of cyclodextrins. Tetrahedron Lett. 1990, 31, 4275-4278. [CrossRef]

30. Kohata, S.; Jyodoi, K.; Ohyoshi, A. Thermal decomposition of cyclodextrins $(\alpha-, \beta-, \gamma-$, and modified $\beta-C y D)$ and of metal-( $\beta-$ CyD) complexes in the solid phase. Thermochim. Acta 1993, 217, 187-198. [CrossRef] 